\title{
Numerical Study on Solidification of Phase Change Materials Embedded with Metal Foam
}

\author{
Mustafa Asker ${ }^{1}\left[\mathbb{C}^{\circ}\right.$, Hadi Genceli ${ }^{2}$ \\ 'Aydın Adnan Menderes University, Faculty of Engineering, Department of Mechanical Engineering, Aydın, Turkey \\ ${ }^{2}$ Avrasya University, Faculty of Engineering, Department of Mechanical Engineering, Trabzon, Turkey
}

\begin{abstract}
This work investigates the solidification of phase change material (PCM) embedded with metal foam (MF) in a spherical capsule which its outer layer is exposed to convective heat transfer. The one-dimensional energy equation is resolved by performing finite volume method accompanied with temperature transforming technique. Four separate scenarios are developed for different porosity value of MF in order to analyze the thermal behavior of composite PCM with MF. The numerical model is validated by experimental data taken from the literature and substantially good agreement is demonstrated. The results show that at the case where the porosity $\varepsilon=0.92$, the elapsed time for complete solidification is decreases by $88 \%$ compared to the case without MF $(\varepsilon=1.0)$.
\end{abstract}

Keywords: Control volume approach; Phase change material; Metal foam; Solidification.

\section{INTRODUCTION}

Several fields of the energy system such as industrial, transportation and buildings sectors have a high priority in energy efficiency researches, due to their highest energy saving potential in total final energy consumption. Energy storage methods come to the forefront for the efficient utilization of renewable and alternative energy sources [1]. Energy can be stored in order to get more benefit from energy sources. Energy storage technologies increase energy efficiency by diminishing mismatch between supply and demand [2]. The search for new and renewable energy sources as well as more efficient solutions for the storage of energy is ongoing. Most of the studies on storage materials have focused on thermal energy storage (TES) systems. Materials that are used in TES systems are known as phase change materials (PCMs) because of their high latent heat, suitable phase change temperature, low volume change during phase change and high storage capacity. There are informative review papers which examined the heat transfer process in the TES system [3,4]. Furthermore, Kenisarin et al. [5] comprehensively reviewed the heat transfer mechanism of PCM in spherical geometry. Pedroso and Domoto [6] analytically examined the solidification within spherical container by utilizing perturbation technique under constant wall temperature. Tao [7] performed a mechanism for the evaluation of solidification time in cylindrical and spherical geometries.
The numerical solution was based on a fixed grid method. Bilir and Ilken [8] examined the solidification of a PCM encapsulated in a cylindrical and spherical geometries. They formulated and solved the dimensionless form of governing equations numerically by utilizing enthalpy approach with control volume method. Erek and Dincer [9] numerically investigated an encapsulated ice TES system with a fluctuated heat transfer coefficient. They reported that the solidification mechanism is essentially managed by the value of the Stefan number, number of capsule row and diameter of capsule. Most common PCMs materials used in the industry have low thermal conductivity, which reduces the efficiency of TES systems. Therefore, these systems alone do not have a good economic justification. In order to improve the performance of TES systems, various methods are handled, the most important of which are: increasing heat transfer area by using fins [10], PCM encapsulation, simultaneous use of multiple PCMs [11] and filling PCMs in shape stable structures [12]. Narasimhan et al. [13] used an enthalpy method to analyze the solidification inside a spherical capsule. In their study, the PCM is integrated with macro particles. Their results showed that the integration of high thermal conductivity particles to PCMs improves the rate of solidification properly. Various researchers have suggested PCMs filled in MFs in order to improve heat transfer process. Due to PCMs have small thermal conductivity that reduces heat exchange, MF is suggested as a key to enhance thermal con- 
ductivity. An integration of PCM in MF has also been recognized to be effective for TES. Therefore, it is reasonable to utilize MFs in order to enhance the efficiency of TES due to their high thermal conductivity. Various MF materials such as $\mathrm{Al}_{2} \mathrm{O}_{3}$, Copper and Nickel have been utilized [14]. Rehman et al. [15] widely reviewed the improved thermal properties of porous/foam metallic and carbon-based materials and heat transfer process in the LHTES of PCM. The thermal behavior of PCM incorporated with MF during melting mechanism are investigated analytically and experimentally by Zhang et al. [16]. The basic objective of this current research study is to examine the thermal characteristics of PCM embedded in MF for TES compared to the PCM without MF. In this context, time wise temperature distribution is performed to determine the appropriate conditions for TES system. In addition, the impact of porosity of MF on the complete solidification of PCM is examined.

\section{MATERIAL AND METHOD}

The spherical capsule model is schematically displayed in Figure 1. The one-dimensional model consists of a spherical capsule of radius $r_{\text {out }}=0.05 \mathrm{~m}$ filled with PCM embedded in MF. The thermo-physical properties of the PCM and MF are given in Table 1 . The melting temperature of the PCM with $T_{m}=0^{\circ} \mathrm{C}$ is lower than its initial temperature $T_{\text {initial }}$. The outer surface of the capsule is exposed to convective cooling which is retained at temperature $T_{f}$ and convective heat transfer coefficient $h$. The latent heat is taken as $\mathrm{L}=333400 \mathrm{~kJ} / \mathrm{kg}$.

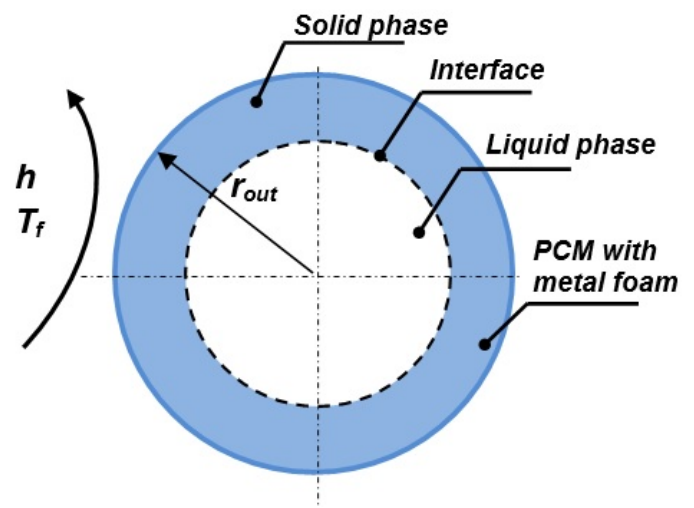

Figure 1. Mathematical model for the spherical capsule embedded with MF.

Table 1. Thermo- physical properties of the PCM and MF $[17,18]$.

\begin{tabular}{|c|c|c|c|}
\hline Properties & Water Solid & Water Liquid & Aluminum \\
\hline Specific heat, $[\mathrm{kJ} / \mathrm{kg} \mathrm{K}]$ & 2040 & 4210 & 902 \\
\hline Thermal conductivity, $[\mathrm{W} / \mathrm{m} \mathrm{K}]$ & 1.88 & 0.567 & 218 \\
\hline Density, $\left[\mathrm{kg} / \mathrm{m}^{3}\right]$ & 916.8 & 998.8 & 2700 \\
\hline
\end{tabular}

The following assumptions are conducted in the mathematical model to simplify the problem:

- The thermal properties of the PCM and MF are independent of temperature. However, the PCM are comprised of two distinct regions which are solid and liquid.

- The PCM is considered homogenous and isotropic.

The temperature transforming method described by Cao and Faghri [19] is used to simulated the heat conduction in the spherical capsule. This technique has considered that the solidification process includes three phases namely, solid, liquid and mushy regions. In order to simplify the problem, the non-dimensional parameters are used and listed in Table 2.

\begin{tabular}{|c|c|}
\hline \multicolumn{1}{|l}{ Table 2. Non-dimensional parameters } \\
\hline Parameters & Definition \\
\hline Radius & $R=\frac{r}{r_{\text {out }}}$ \\
\hline Temperature & $\theta=\frac{T-T_{m}}{T_{m}-T_{f}}$ \\
\hline Specific heat & $C=\frac{(\rho c)}{\rho_{L} c_{L}}$ \\
\hline Thermal conductivity & $K=\frac{k}{k_{L}}$ \\
\hline Source term & $S=\frac{\rho_{L}}{\rho_{L} c_{L}\left(T_{m}-T_{f}\right)}$ \\
\hline Stefan number & $S t e=\frac{c_{L}\left(T_{m}-T_{f}\right)}{L}$ \\
\hline Fourier number & $F o=\frac{\alpha_{L} t}{r_{\text {out }}^{2}}$ \\
\hline Biot number & $B i=\frac{h r_{\text {out }}}{k_{L}}$ \\
\hline
\end{tabular}

The one-dimensional energy equation for spherical capsule expressed in the dimensionless form as

$$
\frac{\partial(C \theta)}{\partial F o}=\frac{1}{R^{2}} \frac{\partial}{\partial R}\left[K R^{2} \frac{\partial \theta}{\partial R}\right]-\frac{\partial S}{\partial F o}
$$

where $C, S$ and $K$ variables described as follows

$$
\begin{aligned}
& C(\theta)=\left\{\begin{array}{lll}
C_{s l} & \theta<-\delta \theta_{m} & \text { Solid } \\
\frac{1}{2}\left(1+C_{s l}\right)+\frac{1}{2 S t e \delta \theta_{m}} & -\delta \theta_{m} \leq \theta \leq \delta \theta_{m} & \text { Mushy } \\
1 & \theta>\delta \theta_{m} & \text { Liquid }
\end{array}\right. \\
& S(\theta)=\left\{\begin{array}{lll}
C_{s l} \delta \theta_{m} & \theta<-\delta \theta_{m} & \text { Solid } \\
{\left[\frac{1}{2} \delta \theta_{m}\left(1+C_{s l}\right)+\frac{1}{2 S t e}\right]} & -\delta \theta_{m} \leq \theta \leq \delta \theta_{m} & \text { Mushy } \\
C_{s l} \delta \theta_{m}+\frac{1}{S t e} & \theta>\delta \theta_{m} & \text { Liquid }
\end{array}\right. \\
& K(\theta)=\left\{\begin{array}{lll}
K_{s l} & \theta<-\delta \theta_{m} & \text { Solid } \\
K_{s l}+\frac{\left(1-K_{s l}\right)\left(\theta+\delta \theta_{m}\right)}{2 \delta \theta_{m}} & -\delta \theta_{m} \leq \theta \leq \delta \theta_{m} & \text { Mushy } \\
1 & \theta>\delta \theta_{m} & \text { Liquid }
\end{array}\right.
\end{aligned}
$$

The initial state for equation (1) is

$$
\text { Fo }=0 \rightarrow \quad \theta=\theta_{\text {initial }}
$$

Whereas the boundary conditions can be written as follows

$$
\begin{aligned}
& R=0 \rightarrow \frac{\partial \theta}{\partial R}=0 \\
& R=1 \rightarrow K \frac{\partial \theta}{\partial R}=-B i(\theta+1)
\end{aligned}
$$

Equations 1 to 7 is resolved by applying the control volume approach as explained in Versteeg and Malalasekera [20] as 
follows:

$$
\int_{V} \int_{F o} \frac{\partial(C \theta)}{\partial F_{O}} d V d F o=\int_{V} \int_{F_{o}} \frac{1}{R^{2}} \frac{\partial}{\partial R}\left[K R^{2} \frac{\partial \theta}{\partial R}\right] d V d F o-\int_{V} \int_{F_{o}} \frac{\partial S}{\partial F_{O}} d V d F o
$$

The discretized non-dimensional energy equation for interior nodes is written in general form as

$$
\begin{aligned}
\frac{C_{P} \theta_{P}-C_{P}^{0} \theta_{P}^{0}}{\Delta F o} \frac{\left(R_{e}^{3}-R_{w}^{3}\right)}{3}=[ & {\left[K_{e} R_{e}^{2} \frac{\theta_{E}-\theta_{P}}{\Delta R_{e}}-K_{w} R_{w}^{2} \frac{\theta_{P}-\theta_{W}}{\Delta R_{w}}\right] } \\
& -\frac{S_{P}-S_{P}^{0}}{\Delta F_{o}} \frac{\left(R_{e}^{3}-R_{w}^{3}\right)}{3}
\end{aligned}
$$

At the control surface, the harmonic mean is used to calculate the thermal conductivity Patankar [21]. Numerical computations are carried out by resolving Equations 1 to 8 . A self-developed computer program coded in $\mathrm{C}++$ language is used to obtain the transient temperature variations. Due to nonlinearity of the energy equations, iterative solution is needed. Based upon the preliminary runs, the time step size and convergence criterion are decided as $0.1 \mathrm{~s}$ and $1 \mathrm{E}-6$, accordingly. Furthermore, the solidified mass fraction (SMF) can be calculated as follows [22].

$$
\text { SMF }=\frac{\text { Mass of solid }}{\text { Total mass }}
$$

In this work, Aluminum as a MF is integrated in PCM to enhance the heat transfer mechanism. Bhattacharya et al. [23] proposed a simple correlation to evaluate the effective thermal conductivity as follows:

$$
k_{e f f}=A\left[\varepsilon k_{P C M}+(1-\varepsilon) k_{A L}\right]+\frac{(1-A)}{\left(\frac{\varepsilon}{k_{P C M}}+\frac{(1-\varepsilon)}{k_{A L}}\right)}
$$

Where $\varepsilon$ represent the porosity and $A$ is constant $(A=0.35)$. Besides, the effective specific heat, density and latent heat correlations are obtained from literature [24].

\section{RESULTS AND DISCUSSION}

This research study performed a numerical analysis in order to investigate the effect of porosity of MF combined with the PCM on solidification process inside spherical capsule. Throughout this work, the Bi number, the phase change temperature ranges and the number of nodes is selected to be 5, 0.01 and 100, respectively. In order to demonstrate the reliability of the solution method, the numerical model that is handled in this study is compared with experimental and numerical data which is published by (Ismail et al. 2003) as shown in Figure 2. The value of $r_{\text {out }}, T_{f}$ and $T_{\text {initail }}$ are fixed at $0.064 \mathrm{~m},-7.5^{\circ} \mathrm{C}$ and $25.8^{\circ} \mathrm{C}$, accordingly. It can be observed that the transient variation of center temperature of the sphere consistence with the experimental and numerical method that is reported in Ismail et al. [22]. Consequently, the present numerical model is suitable to tackle the phase change problem in spherical capsule.

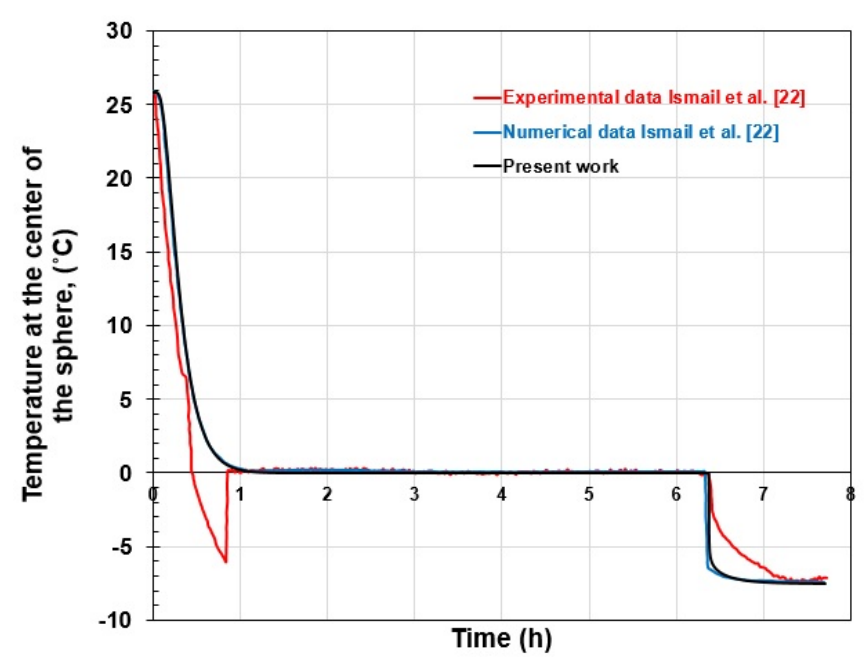

Figure 2. Comparison of the current numerical model with the results obtained from Ismail et al. [22].

In this work, four different cases for studies are established according to the porosity of MF as given in Table 3. In addition, the effective thermal conductivity value for composite solid and liquid statuses of the PCM are also included in Table 3. Case 1 with $\varepsilon=1.0$ represent baseline case in which there is no MF contains within the PCM. Case 2 with $\varepsilon$ $=0.98$, Case 3 with $\varepsilon=0.96$ and Case 4 with $\varepsilon=0.92$ which have higher $k_{\text {eff }}$ compared to the other cases. The effective thermal conductivity of PCM is calculated based on Equation (11). The solidification mechanism begins from the outer layer that is subjected to the heat convection, and advances inward towards the center of the spherical capsule. The solidification process is achieved when the liquid PCM is transformed to solid phase. Hence, the thermal equilibrium of the system has compassed with the outside conditions.

Table 3. Configurations of the effective thermal conductivity for each
\begin{tabular}{|c|c|c|c|}
\hline case. & $\begin{array}{c}k_{\text {eff }} \text { (solid) } \\
{[\mathrm{W} / \mathrm{m} . \mathrm{K}]}\end{array}$ & $\begin{array}{c}k_{\text {eff }} \text { (liquid) } \\
{[\mathrm{W} / \mathrm{m} . \mathrm{K}]}\end{array}$ \\
\hline 1 & $\begin{array}{c}\text { Porosity } \\
(\varepsilon)\end{array}$ & 1.88 & 0.567 \\
\hline 2 & 1.0 & 3.417 & 2.096 \\
\hline 3 & 0.98 & 4.956 & 3.626 \\
\hline 4 & 0.96 & 8.037 & 6.687 \\
\hline
\end{tabular}

Figure 3 illustrates the time wise variation of center temperature for different cases. In general, the center temperature of the sphere which is originally at liquid status drops until it finally becomes constant as it proceeds to the mushy region then abruptly reduces to its final situation which is the solid phase. It can be seen that Case 4 needs remarkably lower solidification time compared to the baseline case (Case 1) because the heat conduction mechanism is high that makes the solidification process to occurs rapidly. Figure 4 depicts the time wise variation of SMF for different cases. In this figure, initially the PCM is at liquid phase and the SMF is at its minimum position $(S M F=0)$ and increases until it eventually reaches to its maximum point $(S M F=1)$ which means that the complete solidification is taken place. It can be observed that the SMF trend for Case 4 with $(\varepsilon=0.92)$ occurs 
faster than the other cases because of the $k_{\text {eff }}$ values of Case 4 is larger than the other cases.

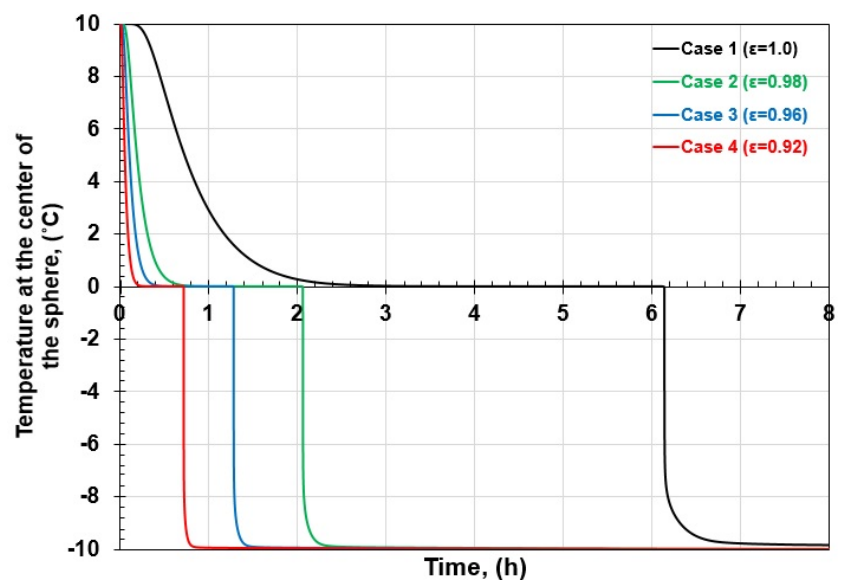

Figure 3. Evolution of temperature for different MF porosity.

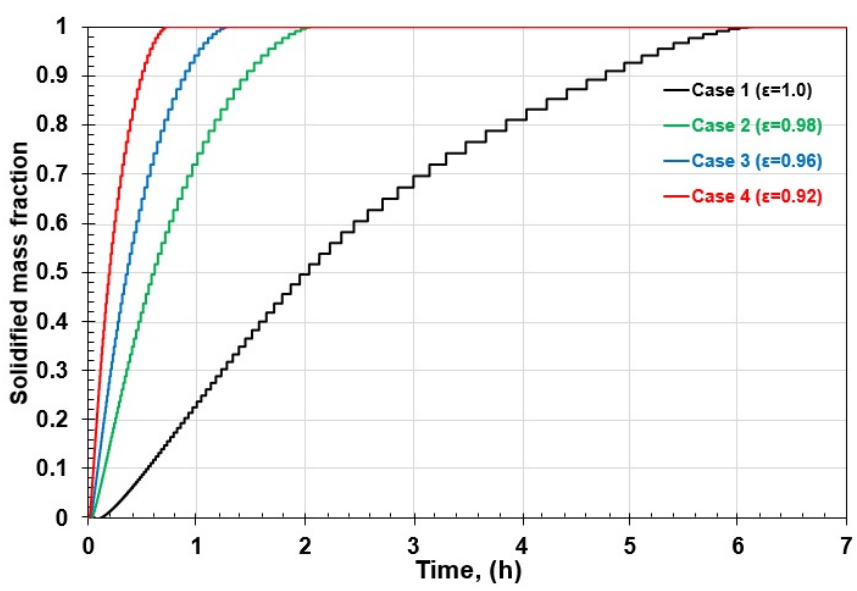

Figure 4. Effect of porosity of metal foam on solidified mass fraction.

Figure 5 demonstrates that the time for complete solidification for Case 1 with $(\varepsilon=1.0)$ can be achieved at about 6.13 hours while for Case 4 with $(\varepsilon=0.92)$ the complete solidification can be reached after about 0.72 hour. This is due to the effective thermal conductivity for both solid and liquid phases in Case 4 are higher than the other cases (see Table 3) which enhances the heat conduction processes.

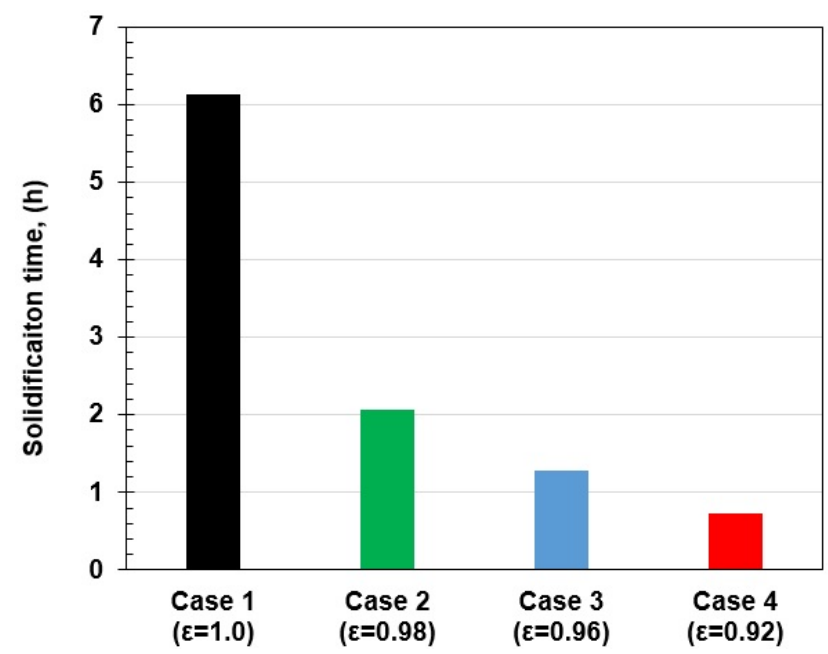

Figure 5. Time for complete solidifcation for different cases.

Figure 6 illustrates the characteristics of temperature profile for surface and center temperatures of the PCM incorporated with MF inside spherical capsule. In this figure, Case 3 with $\varepsilon=0.96$ is considered. In this figure, the center portion of the sphere temperature initially at liquid status for about 24 min whereas the solid region at the center begins after about $1.28 \mathrm{~h}$. between these two durations, the mushy phase occurs. The abrupt drop in center temperature after $1.28 \mathrm{~h}$ can be attributed to the extracting sensible heat from the solidified portion whereas phase change be formed at the conversion from mushy region to solid status.

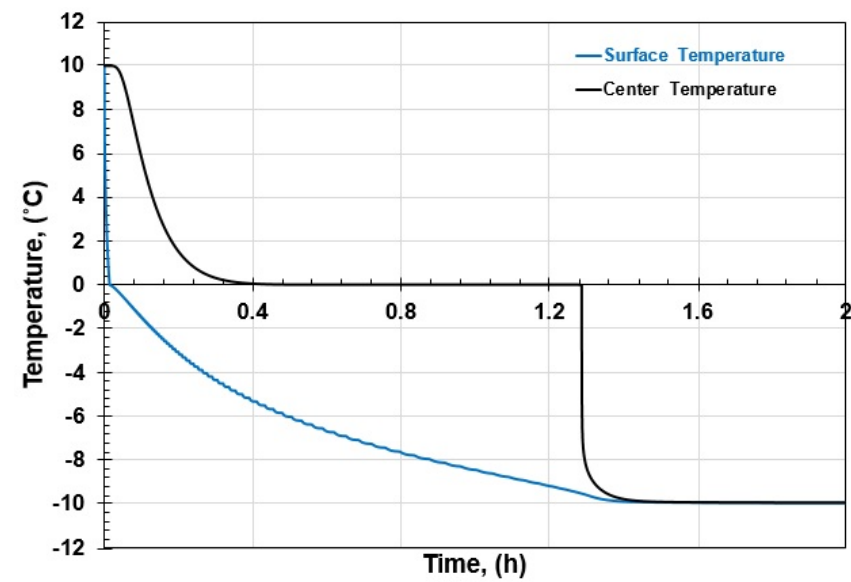

Figure 6. Time wise variation of temperatures for composite PCM with metal foam.

\section{CONCLUSIONS}

This study examined the solidification of PCM integrated with MF in spherical capsule by applying the finite volume technique. The proposed model is validated with previously published work. The thermal characteristics of the center temperature for various porosity is simulated. It can be concluded that the effective thermal conductivity will be significantly improved by adding MF to the PCM. In addition, a higher $k_{e f f}$ results in a higher heat conduction and as a result, faster solidification process is achieved. In this context, the use of MF is a reasonable approach for enhancing the heat transfer in TES systems. In addition, the criteria required for the design of TES can be determined based on these analyzes.

\section{REFERENCES}

[1] Dincer I., Rosen, M.A. (2011). Thermal Energy Storage Systems and Applications. 2nd ed., Wiley, New York.

[2] Dincer, I., Ezan M.A. (2018). Heat Storage: A Unique Solution for Energy Systems. 1st ed. Springer, Switzerland.

[3] Regin, A. F., Solanki, S.C., Saini, J.S. (2017). Heat transfer characteristics of thermal energy storage system using PCM capsules: A review. Renewable and Sustainable Energy Reviews, 12(9): 2438-2458, DOI: 10.1016/j.rser.2007.06.009.

[4] Koohi-Fayegh, S., Rosen, M.A. (2020). A review of energy storage types, applications and recent developments. Journal of Energy Storage, 27: 101047, DOI: 10.1016/j.est.2019.101047.

[5] Kenisarin, M.M., Mahkamov, K., Costa, S.C., Makhkamova, I. (2020). Melting and solidification of PCMs inside a spherical capsule: A critical review. Journal of Energy Storage, 27: 101082, DOI: 10.1016/j. est.2019.101082.

[6] Pedroso, R.I., Domoto, G.A. (1973). Perturbation solutions for sphe- 
rical solidification of saturated liquids. Journal of Heat Transfer, 95 (1): 42-46, DOI: 10.1115/1.3450002.

[7] Tao, L.C. (1967). Generalized numerical solutions of freezing a saturated liquid in cylinders and spheres. AIChE Journal, 13 (1): 165-169, DOI:10.1002/aic.690130130.

[8] Bilir, L., Ilken, Z. (2005). Total solidification time of a liquid phase change material enclosed in cylindrical/spherical containers. Applied Thermal Engineering, 25(10):1488-1502, DOl:10.1016/j.applthermaleng.2004.10.005.

[9] Erek, A., Dincer, I. (2009). Numerical heat transfer analysis of encapsulated ice thermal energy storage system with variable heat transfer coefficient in downstream. International Journal of Heat and Mass Transfer, 52(3-4): 851-859, DOI:10.1016/j.jijheatmasstransfer.2008.06.024.

[10] Gharebaghi, M., Sezai, I. (2007). Enhancement of Heat Transfer in Latent Heat Storage Modules with Internal Fins. Numerical Heat Transfer, Part A: Applications, 53(7): 749-765, DOI:10.1080/10407780701715786.

[11] Asker, M., Alptekin E., Ezan M.A., Ganjehsarabi H. (2018). Entropy generation analysis of multilayer PCM slabs integrated with fins. International Journal of Exergy, 26(1-2): 154-169, DOI: 10.1504/ IJEX.2018.092511.

[12] Sari, A., Karaipekli, A. (2007). Thermal conductivity and latent heat thermal energy storage characteristics of paraffin/expanded graphite composite as phase change material. Applied Thermal Engineering, 27(8-9): 1271-1277, DOI: 10.1016/j.applthermaleng.2006.11.004.

[13] Narasimhan, N. L., Veeraraghavan, V., Ramanathan, G., Bharadwaj, B. S., Thamilmani, M. (2018). Studies on the inward spherical solidification of a phase change material dispersed with macro particles. Journal of Energy Storage, 15: 158-171, DOI: 10.1016/j.est.2017.10.016.

[14] Welsford, C., Bayomy, A. M., \& Saghir, M. Z. (2018). Role of metallic foam in heat storage in the presence of nanofluid and microencapsulated phase change material. Thermal Science and Engineering Progress, 7: 61-69, DOI: 10.1016/j.tsep.2018.05.003.

[15] Rehman, T., Ali, H. M., Janjua, M. M., Sajjad, U., Yan, W.M. (2019). A critical review on heat transfer augmentation of phase change materials embedded with porous materials/foams. International Journal of Heat and Mass Transfer, 135: 649-673, DOl:10.1016/j.ijheatmasstransfer.2019.02.001.

[16] Zhang, Z., Wang, Z., He, X. (2020). Analytical solution of the melting process of phase-change materials in thermal energy storage system. Energy Sources, Part A: Recovery, Utilization, and Environmental Effects, 1-16, DOI:10.1080/15567036.2020.1779413.

[17] Asker, M., Ganjehsarabi, H., Coban, M.T. (2018). Numerical investigation of inward solidification inside spherical capsule by using temperature transforming method. Ain Shams Engineering Journal, 9(4): 537-547, DOI: https://doi:org/10.1016/j.asej.2016.02.009.

[18] Incropera, F., Dewit, D., Bergman, T., Lavine, A. (2007). Fundamentals of Heat and Mass Transfer. 6th ed., Wiley, New York.

[19] Cao, Y., Faghri A., (1990) A numerical analysis of phase-change problem including natural convection. ASME Journal of Heat Transfer, 112: 812-816, DOI: https://doi.org/10.1115/1.2910466

[20] Versteeg, H.K. Malalasekera, W. (1995). An introduction to computational fluid dynamics: The finite volume method. Prentice Hall, London.

[21] Patankar, S.V. (1980). Numerical Heat Transfer and Fluid Flow. McGraw-Hill, New York.
[22] Ismail, K.A.R., Henriquez, J.R., da Silva T.M. (2003). A parametric study on ice formation inside a spherical capsule. International Journal of Thermal Sciences, 42(9): 881-887, DOI: https://doi.org/10.1016/ S1290-0729(03)00060-7

[23] Bhattacharya, A., Calmidi, V.V., Mahajan, R.L. (2002). Thermophysical properties of high porosity metal foams. International Journal of Heat Mass Transfer 45(5): 1017-1031, DOl: https://doi.org/10.1016/ S0017-9310(01)00220-4.

[24] Venkateshwar K., Tasnim, S.H. Simha H., Mahmud S. (2020). Empirical correlations to quantify the effect of metal foam on solidification process in constant thermal capacity and constant volume systems, Journal of Energy Storage, 30: 101482, DOI: https://doi.org/10.1016/j.est.2020.101482. 